\title{
Los asbestos y las soluciones judiciales *
}

\author{
Asbestos and Judicial Solutions
}

Carlos Andrés Uribe Piedrahita ${ }^{\text {a }}$

Pontificia Universidad Javeriana, Colombia

uribecarlos@javeriana.edu.co

ORCID: http://orcid.org/0000-0002-0450-4340
DOI: https://doi.org/10.11144/Javeriana.vj138.asju Redalyc: http://www.redalyc.org/articulo.oa?id=82559799001

¿Esperar más de 13 años por una decisión de primera instancia sobre una acción popular contra el asbesto y determinar la relación que debe tener la sociedad con ese mineral es el estándar de justicia que deben aceptar los colombianos?

Para aproximarnos a esta discusión, propongo dos líneas de análisis: de un lado, el mensaje que envía a la sociedad la protección judicial de los derechos colectivos cuando un caso puede durar solo en primera instancia, más de 13 años; de otro lado, explorar las alternativas de la protección de la sociedad frente al asbesto.

El 1 de marzo de 2019, el Juzgado 39 Administrativo del Circuito de Bogotá decidió en primera instancia una acción popular interpuesta por JUAN JOSÉ LALINDE SUÁREZ, con el fin de evitar que se continuara con la violación de diferentes derechos colectivos por razón del uso y contacto con el asbesto en Colombia, informando del peligro que enfrentan las personas de cara al asbesto que está "presente entre el público en construcciones, vehículos y otros materiales", como también, para que se tomaran las medidas necesarias para prohibir su explotación, uso, comercialización, entre otras diferentes actividades, acorde con la Ley 436 de 1998, sobre la utilización del asbesto en condiciones de seguridad, en atención al Convenio 162 de la Organización Internacional del Trabajo, OIT. Por medio de esta acción, se demandó al Ministerio de la Protección Social (hoy Ministerio del Trabajo y Ministerio de Salud y Protección Social), Corporación Autónoma Regional de Antioquia, Corantioquia, y la compañía minera Las Brisas S.A. (hoy Bricolsa), con el objetivo de que esta última terminara la explotación minera del asbesto, mientras que a las demás se les demandaba para que se asegurara el cierre de la mina y la terminación de cualquier actividad de explotación de este material ${ }^{1}$.

Las acciones populares son el medio procesal con que cuentan los ciudadanos para la protección de los derechos e intereses colectivos, esto es, acciones que se ejercen para proteger derechos comunes a todos los individuos de una colectividad.

El trámite procesal en primera instancia de la presente acción popular inició el 15 de diciembre de 2005 , 13 años y dos meses y medio después, el 1 de marzo de 2019 fue decidida por el Juez 39 Administrativo del Circuito de Bogotá. Al 22 de marzo, la sentencia ha sido apelada por 13 actores y recurrida en reposición en un caso. Este hecho nos puede indicar que el proceso continuará y que para que haya una decisión en firme, la Tierra girará alrededor del Sol numerosas veces.

La sentencia señala en el apartado XII, asuntos previos (páginas169-171) que los procesos deben tener un plazo razonable para un fallo, indicando que en el presente caso ocurrieron dos tipos de sucesos: de un lado, el conocimiento de los posibles casos de exposición al asbesto durante el desarrollo probatorio, haciendo necesaria la reorientación del proceso, para incluir un mayor número de sujetos procesales, empleadores, agentes estatales, sector minero, productores de bienes que contenían asbesto, etc. De otro lado, la sentencia reconoce dos condiciones exógenas al proceso: tres paros judiciales y 250 acciones de tutela interpuestas

Notas de autor:

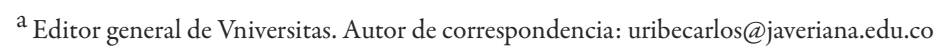


y negadas, como también condiciones propias del desarrollo del procedimiento por su dimensión, los testimonios, la necesidad de colaboración requerida a otros despachos judiciales, entre otras consideraciones que, en términos del juzgado, exigieron prolongar la permanencia del proceso.

Recientemente, el Consejo Superior de la Judicatura presentó al Congreso de la República el Informe de Gestión sobre la Administración de Justicia, en el que señaló que para 1993 en el inventario final de procesos se acumulaban 24 de cada 100 ingresos, mientras que en 2018, este índice es de 17 procesos. Así, entre 1993 y 2018, el Índice de Evacuación Parcial (IEP) ${ }^{2}$ se redujo en 7 puntos porcentuales y hubo una mejora, pero refleja igualmente la existencia de problemas en la atención de justicia. Ante el déficit en la oferta de la justicia, el Consejo Superior subraya que, cada vez más incrementa la demanda de justicia, como la población, sin que haya un aumento proporcional de despachos judiciales; la causa de esta brecha es la falta de presupuesto.

El informe del Consejo Superior de la Judicatura al Congreso de la República ${ }^{3}$, en el año 2017, detectó que la demanda por la justicia en los últimos 25 años, casi todo el período desde la promulgación de la Constitución Política de 1991, ha incrementado en 269\%, mientras que la oferta de justicia solo se ha incrementado en $39 \%$, por lo cual se requiere un ajuste estructural que permita equilibrar las necesidades de justicia. El ingreso anual de procesos sigue siendo más alto que el egreso anual en la sumatoria de la Rama Judicial y hay que sumarle, a su vez, los inventarios que vienen de los años anteriores. La forma como se ha tratado de mermar el resultado negativo del cumplimiento decisional efectivo, se resume en una mayor eficiencia del recurso humano de la Rama y en la formulación de normas de descongestión que permitieron la inclusión de instituciones de desistimiento tácito y perención, y de normas que facilitaron la terminación anticipada de los procesos por transacción y conciliación, principalmente. Sin embargo, el principal problema continúa: la falta de inversión estructural y de recurso humano que se refleje en la ampliación del servicio de justicia con un mayor número de jueces, de juzgados y tribunales, que permitan una mejor relación entre los asuntos que entran y aquellos que son resueltos; y también para lograr que las acciones de tutela no congestionen la función ordinaria de la jurisdicción, claro está, sin que se reduzca la protección de los derechos fundamentales y colectivos de la sociedad.

En definitiva, la existencia de un problema estructural en la administración de justicia para dar respuestas oportunas a los procedimientos judiciales; la existencia de casos complejos, con procedimientos especiales (que permiten que se extiendan en el tiempo) y que definen situaciones de derecho que lindan con la ejecución de políticas públicas; y la ponderación de múltiples derechos individuales y colectivos, constituyen una fórmula perversa para dar soluciones eficaces en tiempo a las necesidades de la sociedad. Esto parece enseñárnoslo el presente asunto contra el asbesto.

Como lo habíamos planteado, es necesario explorar las alternativas de la protección de la sociedad frente al asbesto, reconocer la importancia de la actividad judicial frente a la protección colectiva de derechos y señalar que las intervenciones regulatorias pueden estar mejor ubicadas para dar soluciones efectivas y eficientes a los problemas colectivos.

En el marco de la protección efectiva de los derechos contenidos en la Constitución, los jueces han desarrollado protecciones estructurales bajo intervenciones de impacto general ante violaciones continuas, amplias y sistemáticas de los derechos de la población. Esta intervención estructural se manifiesta en la obligación de los jueces, como poder público, de la crítica al estado de cosas existente mediante una intervención de la naturaleza del diseño e implementación de políticas públicas que benefician a un número mayor de personas, diferentes de aquellas que acudieron a la jurisdicción para la protección efectiva de los derechos.

Para determinar la existencia de un estado de cosas inconstitucional, la Corte Constitucional ha señalado que deben concurrir seis factores:

[...] (i) La vulneración masiva y generalizada de varios derechos constitucionales que afecta a un número significativo de personas; (ii) la prolongada omisión de las autoridades en el cumplimiento de sus obligaciones para garantizar los derechos; (iii) la adopción de prácticas inconstitucionales, como la incorporación de la acción de tutela como parte del procedimiento 
para garantizar el derecho conculcado; (iv) la no expedición de medidas legislativas, administrativas o presupuestales necesarias para evitar la vulneración de los derechos; (v) la existencia de un problema social cuya solución compromete la intervención de varias entidades, requiere la adopción de un conjunto complejo y coordinado de acciones y exige un nivel de recursos que demanda un esfuerzo presupuestal adicional importante; (vi) si todas las personas afectadas por el mismo problema acudieran a la acción de tutela para obtener la protección de sus derechos, se produciría una mayor congestión judicial $^{4}$.

Los factores señalados por la Corte Constitucional explican suficientemente la necesidad de intervención judicial frente a un problema de naturaleza estructural de protección de derechos. En especial, para efectos de lo presentado acá, nos encontramos con circunstancias que pretenden generar un menor uso del sistema judicial como consecuencia de la falta de acción del Ejecutivo, esto es, de un lado, el uso de la acción de tutela como mecanismo procedimental (cuasiordinario) para la protección de derechos y, de otro lado, la potencialidad de un mayor desgaste de la administración de justicia mediante el uso masivo de la acción de tutela como medio para la protección de derechos. Igualmente, al enfrentar el estado de cosas inconstitucional, la Corte pone de presente, en un sentido, la falta de intervención de los otros poderes públicos para dar una solución efectiva a la violación colectiva de derechos, tanto el Legislativo como el Ejecutivo, bien en su acción o en su planeación presupuestal, mientras que, en otro sentido, llama a la coordinación de diferentes entidades y la materialización presupuestal para poner en marcha la protección de los derechos. Esta última característica puede ser considerada como el bloqueo institucional que ha dado lugar a la existencia de la necesidad de protección estructurada de derechos por parte de los jueces 5 .

Por ejemplo, en la sentencia del Juzgado 39 Administrativo del Circuito de Bogotá, D. C., se tomaron diferentes medidas con el fin de que la protección estructural de diferentes derechos colectivos fuera una realidad. Entre las medidas más relevantes — la sentencia tiene más de veinte órdenes a diferentes entidades, públicas y privadas-, nos encontramos con la orden a la Nación para que sustituya el asbesto en un término máximo de cinco años, la realización de inventarios sobre las empresas que usan asbestos, los comercializadores, las redes de servicio público que contienen asbesto y, para este último caso, el inventario se adelantará en un año, y en los siguientes cuatro años, se sustituirá el asbesto. Igualmente se ordenó el cierre de una mina de asbesto, el seguimiento a dicho desmonte, la orden a las empresas que producen bienes que contienen asbesto, la obligación de señalar que el producto contiene asbesto, etc.

Por último, hay una diferencia entre jueces y autoridades administrativas (regulatorias): los primeros son generalistas y los segundos, expertos en su campo de conocimiento. Por lo general, el argumento que se esgrime para señalar que los jueces no deben hacer exámenes de políticas públicas es que estos análisis deben quedar en cabeza de expertos. Sin embargo, este argumento omite que las agencias administrativas también pueden cometer errores; además, las mismas pueden tener desviaciones, conscientes o inconscientes, que influencian cómo se regula. En el presente caso, el problema parece encontrarse en la no existencia de estudios independientes, amplios, convincentes y que fueran abordados en clave de construcción de una política pública por parte de alguna agencia administrativa (por ejemplo, el Ministerio de Salud y Protección Social, o el Ministerio del Trabajo) para conocer los costos y beneficios de la producción de asbestos en Colombia ${ }^{6}$. Por el contrario, lo que ha sucedido es una forma de administrar la convivencia con el asbesto, principalmente, como medidas de salud ocupacional. En este sentido, no es de extrañar que al final del camino, la política pública de la producción y de desarrollo a base de asbesto sea adelantada por los jueces como medio para garantizar derechos de la sociedad.

En conclusión, no parece especialmente alarmante que los jueces tengan injerencia en la construcción de políticas públicas, tanto bajo el estado de cosas inconstitucional, como bajo las decisiones de acciones populares que afectan derechos colectivos; sin embargo, es preocupante que una acción colectiva pueda tardar más de trece años en una primera instancia para plantear la construcción de una política pública, que continuará con debates en otras instancias judiciales. En este mismo sentido, preocupa que las decisiones de políticas públicas que realizan los jueces no cuenten con insumos, o puedan ser contrastadas, con estudios 
de costo-beneficio que permitan ilustrar la idea de bienestar que se pretende alcanzar con la prohibición del asbesto en Colombia.

\section{Bibliografía}

\section{Libros}

GUTIÉRREZ-BELTRÁN, ANDRÉS MAURICIO, El amparo estructural de los derechos (Centro de Estudios Constitucionales, Madrid, 2018).

VILLAMIZAR, GUILLERMO, Asbestos en Colombia: una verdad inocultable, en Asbesto en Colombia. Fundamentos para el Debate, 131-144 (GUILLERMO VILLAMIZAR \& GABRIEL CAMERO-RAMOS, comps., Universidad Nacional, Bogotá, 2019).

\section{Colaboración en obras colectivas}

OSUNA, NÉSTOR, Las sentencias estructurales. Tres ejemplos de Colombia, en Justicia Constitucional No. 5. La protección de los derechos sociales. Las Sentencias estructurales, 91-116 (VÍCTOR BAZÁN, ed., Konrad-AdenauerStiftung, Berlín, Bogotá, 2015). Disponible en: https://www.kas.de/c/document_library/get_file?uuid=7bc14 9f4-967c-225c-ba7f-4c0351289cff\&groupId=252038

\section{Revistas}

HENAO-PÉREZ, JUAN CARLOS, El juez constitucional: un actor de las politicas públicas, 15 Revista de Economía Institucional, 29, 67-102 (2013). Disponible en: https://www.economiainstitucional.com/pdf/No29/jhenao2 9.pdf

\section{Referencias}

Convenios y tratados internacionales

\section{Legislación colombiana}

Colombia, Ley 436 de 1998, por medio de la cual se aprueba el Convenio 162 sobre utilización del asbesto en condiciones de seguridad, adoptado en la $72^{\text {a }}$ Reunión de la Conferencia General de la Organización Internacional del Trabajo, Ginebra, 1986, 43.241 Diario Oficial, 19 de febrero de 1998. Disponible en: http:// www.suin-juriscol.gov.co/viewDocument.asp?id=1832839

\section{Jurisprudencia colombiana}

Colombia, Consejo Superior de la Judicatura, Informe al Congreso de la República, 2018. Disponible en: https://ww w.ramajudicial.gov.co/documents/10240/15989223/Informe+al+congreso+2017.pdf

Colombia, Corte Constitucional, Sentencia T-025-04, 22 de enero de 2004, magistrado ponente Manuel José CepedaEspinosa. Disponible en: http://www.corteconstitucional.gov.co/relatoria/2004/t-025-04.htm

Corte Constitucional, Sentencia T-388-13, 28 de junio de 2013, magistrada ponente María Victoria Calle-Correa. Disponible en: http://www.corteconstitucional.gov.co/relatoria/2013/t-388-13.htm

Corte Constitucional, Sentencia T-302-17, 8 de mayo de 2017, magistrado ponente Aquiles Arrieta-Gómez. Disponible en: http://www.corteconstitucional.gov.co/relatoria/2017/t-302-17.htm

Colombia, Corte Constitucional, Sentencia T-267-18, 10 de julio de 2018, magistrado ponente Carlos Bernal-Pulido. Disponible en: http://www.corteconstitucional.gov.co/relatoria/2018/t-267-18.htm 
Colombia, Juzgado 39 Administrativo del Circuito de Bogotá, D.C., Sección Cuarta, Sentencia de 1 de marzo de 2019, Expediente 25000-23-15-000-2005-02488, Accionante Juan José Lalinde Suárez, Accionado Ministerio de la Protección Social y Otros, Juez Leonardo Galeano Guevara. Disponible en: http://www.legisaldia.com/Banco Medios/Archivos/sent-25000231500020050248801-19.pdf

\section{Notas}

* Editorial

1 Colombia, Juzgado 39 Administrativo del Circuito de Bogotá, D.C., Sección Cuarta, Sentencia de 1 de marzo de 2019 , Expediente 25000-23-15-000-2005-02488, Accionante Juan José Lalinde Suárez, Accionado Ministerio de la Protección Social y Otros, Juez Leonardo Galeano Guevara.

2 El Índice de Evacuación Parcial (IEP) se obtiene del cociente entre los egresos y los ingresos de procesos, como porcentaje, y permite determinar la acumulación de procesos del inventario final.

3 Colombia, Consejo Superior de la Judicatura, Informe al Congreso de la República, 2018.

4 Colombia, Corte Constitucional, Sentencia T-025-04, 22 de enero de 2004, magistrado ponente Manuel José CepedaEspinosa. También reiterado en los asuntos, hacinamiento de la población carcelaria, sentencias T-388-13 y T-267-18; igualmente, el estado de cosas inconstitucional del goce de derechos a la alimentación, salud y agua potable de menores wayúu, en La Guajira, sentencia T-302-17. Corte Constitucional, Sentencia T-388-13, 28 de junio de 2013, magistrada ponente María Victoria Calle-Correa. Corte Constitucional, Sentencia T-267-18, 10 de julio de 2018, magistrado ponente Carlos Bernal-Pulido. Corte Constitucional, Sentencia T-302-17, 8 de mayo de 2017, magistrado ponente Aquiles Arrieta-Gómez.

5 ANDRÉS MAURICIO GUTIÉRREZ-BELTRÁN, El amparo estructural de los derechos, 46-48 (Centro de Estudios Constitucionales, Madrid, 2018). NÉSTOR OSUNA, Las sentencias estructurales. Tres ejemplos de Colombia, en Justicia constitucional No. 5. La protección de los derechos sociales. Las sentencias estructurales, 91-116 (VÍCTOR BAZÁN, ed., Konrad-Adenauer-Stiftung, Berlín, Bogotá, 2015). JUAN CARLOS HENAO-PÉREZ, El juez constitucional: un actor de las políticas públicas, 15 Revista de Economía Institucional, 29, 67-102 (2013).

6 Una crítica a los estudios del asbesto en Colombia se encuentra en GUILLERMO VILLAMIZAR, Asbestos en Colombia: una verdad inocultable, en Asbesto en Colombia. Fundamentos para el Debate, 131-144 (GUILLERMO VILLAMIZAR \& GABRIEL CAMERO-RAMOS, comps., Universidad Nacional, Bogotá, 2019).

\section{Licencia Creative Commons CC BY 4.0}

Para citar este editorial / To cite this editorial: URIBE PIEDRAHITA, CARLOS ANDRÉS, Los asbestos y las soluciones judiciales, 138 Vniversitas (2019). https://doi:10.11144/Javeriana.vj138.asju 